\section{Is a mega-project the ELI in the room?}

Romania is firmly committed to contributing to the prestigious Extreme Light Infrastructure (ELI) nuclear physics project, co-funded by the European Regional Development Fund (www.eli-np.ro). As a director of university research grants - hence one of the many possible competitors of ELI for government funding - I support this commitment.

Started in 2013 and due to go live in 2018, ELI is already competing in budget size with the more than US\$100 million that represents the annual total offered by the country's opencompetition national grant schemes (see go.nature.com/ $\operatorname{raad} 8 w)$.

Romania's national research budget has been notably stable over the past five years - and yet individual grants have been shrinking. Explanations have included the relative priorities of different fields or grant types, the international financial crisis, and ethical issues (see, for example, go.nature.com/j8slvh).

With the economic problems fading away and ELI advancing rapidly, an increase in the national research budget would seem logical - and would in fact have precedents. Alternatively, Romania's research ministry may wish to seek support from other ministries, such as those that specialize in infrastructure. Radu Silaghi-Dumitrescu Babeş-Bolyai University, ClujNapoca, Romania. rsilaghi@chem.ubbcluj.ro

\section{Antibodies: validate recombinants once}

It goes without saying that recombinant antibodies, like all binding reagents, need to be validated at the outset (see R. D. Polakiewicz Nature 518, 483 (2015) and L. P. Freedman Nature 518, 483 (2015)). However, we anticipate that recombinant antibodies will require only one such extensive characterization unlike conventionally raised antibodies.

This single validation will assure scientists that antibodies with identical sequences will have similar reactivity profiles - subject to routine checks that binding activity has not been compromised during transit or by storage conditions.

We are aware that our proposal is incompatible with current business models for commercial reagent antibodies. We do not believe that the answer is to defend the status quo, which has not served science well (A. Bradbury and A. Plückthun Nature 518, 27-29; 2015). The solution is to develop more imaginative business strategies that are compatible with the marketing of fully validated, publicly available recombinant antibody sequences.

Andrew M. Bradbury Los Alamos National Laboratory, New Mexico, USA.

Andreas Plückthun University of Zurich, Switzerland. amb@lanl.gov

\section{Inform public on GM, don't cheerlead}

Qiang Wang urges China's scientists to support the government in convincing a sceptical public about the benefits of genetic modification (GM) of agricultural crops (Nature 519, 7; 2015). But there is a distinct line between improving scientific communication and cheerleading for the technology itself.

Scientists should not be in the business of "persuading" the public, nor should they compromise their credibility through hyperbole and oversimplification. Their role is to collect data objectively and use the information to accurately convey the possible risks and benefits.
Scientists should never feel compelled to take sides in polemics, only to present the facts as they understand them. Yongbo Liu, Junsheng Li Chinese Research Academy of Environmental Sciences, Beijing, China.

C. Neal Stewart Jr University of Tennessee, Knoxville,

Tennessee, USA.

liuyb@craes.org.cn

\section{Zero net emissions from Venter facility}

You raise the difficult question of reducing the huge carbon footprint associated with research institutions (Nature 519, 261; 2015). We draw your attention to the J. Craig Venter Institute in California: a clean, green scientific research building that could be a model for others.

Decisions made on building designs now will affect carbon emissions for many decades. In designing the new institute, a genomics research facility, we took responsibility for drastically cutting carbon emissions from its daily operations for the next 50 years or so.

We completely covered the roof with photovoltaic panels, which generate 485 kilowatts of power, which alone would have met only $25 \%$ of the energy needs of a typical 4,200-squaremetre building. Yet the innovative building design is highly energy-efficient and cuts energy demand by $75 \%$ through, for example, heating and cooling with water rather than air; recovery and reuse of 'waste' heat from the water-cooled, $-80^{\circ} \mathrm{C}$ freezers; chemical sensors that allow fewer air exchanges each hour while improving lab safety; deploying operable windows in the office wing; and using natural daylight throughout.

As a result, we have created a laboratory workplace that operates with zero net carbon emissions.

J. Craig Venter, Robert M. Friedman J. Craig Venter
Institute, La Jolla, California, USA.

rfriedman@jcvi.org

\section{Bury botany's outdated image}

Botany courses at academic institutions are dwindling worldwide, yielding too few graduates to replace retiring botanists (see, for example, go.nature.com/sdcagw). Yet botanical expertise is fundamental to a range of topical issues, including biodiversity, agricultural development, biofuel production, drug discovery and food science.

The public can find it hard to differentiate between even common plants, so botanists should engage more in outreach efforts. They also need to devise fresh approaches to teaching upcoming generations about the importance of plants, relying less on pressed dead specimens and focusing on new molecular and systematic tools. This more contemporary treatment of the subject could help to counter botany's lack of appeal to students and researchfunding agencies.

Only then can courses move beyond standard taxonomy to important applications such as the discovery of new genes and gene functions. Let public outreach bury botany's old-fashioned image once and for all.

Isabel Marques University of British Columbia, Vancouver, Canada; and University of Zaragoza, Huesca, Spain. isabel.ic@gmail.com

CONTRIBUTIONS Correspondence may be sent to correspondence@ nature.com after consulting the guidelines at http:// go.nature.com/cmchno. Alternatively, readers may comment online: www.nature.com/nature. 